\title{
Recruitment of the Rod Pathway by Cones in the Absence of Rods
}

\author{
Enrica Strettoi, ${ }^{1}$ Alan J. Mears, ${ }^{2}$ and Anand Swaroop ${ }^{2,3}$ \\ ${ }^{1}$ Istituto di Neuroscienze del Consiglio Nazionale delle Ricerche, 56100 Pisa, Italy, and Departments of ${ }^{2}$ Ophthalmology and Visual Sciences and ${ }^{3}$ Human \\ Genetics, University of Michigan, Ann Arbor, Michigan 48105
}

\begin{abstract}
In mammalian retinas, rods and cones connect to distinct sets of bipolar cells. In the retina of $\mathrm{Nrl}$ (neural retina leucine zipper) knock-out mice, in which rods fail to form and all photoreceptors are cones, rod bipolar cells have normal morphology, pattern of staining, and lamination, but they form synaptic connections with cones. Hence, retinal interneurons are not entirely committed to the choice of their synaptic partners; also, their morphology and pattern of distribution of their processes in the synaptic layers of the retina are not instructed by the establishment of synaptic connections with cognate photoreceptor(s). These findings are of considerable relevance for our understanding of mechanisms responsible for cell recognition during development and in the context of using transplanted tissue to restore vision in retinal degeneration.
\end{abstract}

Key words: cone; rod; horizontal cell; retina; synapse; bipolar cell

\section{Introduction}

Development of the complex network of processes required for neuronal computation is controlled by molecular interactions in the microenvironment and by genetic cues. Correct trajectory of axonal growth cones is guided by numerous factors, including synaptic activity, which can drive rearrangement of connectivity (Katz and Shatz, 1996; Sengpiel and Kind, 2002). An open issue in CNS development is to what extent afferent inputs dictate the development of neuronal circuits. In many developing systems, afferent neurons influence the survival, morphology, and layering of target cells. In turn, target neurons play a crucial role in the establishment or refinement of projections and in the survival of afferents (Buffelli et al., 2003; Kasthuri and Lichtman, 2003).

The vertebrate retina contains rod and cone photoreceptors, precisely tuned to respond to low- and high-intensity light levels, respectively. In the human and rodent retina, rods constitute 95-97\% of photoreceptors (Curcio et al., 1990; Jeon et al., 1998). Partially overlapping yet distinct chains of neurons connect rods and cones to ganglion cells, the final retinal neurons. Cones are presynaptic to at least 10 different types of cone bipolar cells that synapse onto ganglion cells. Rods connect to a single type of rod bipolar cell, which is presynaptic to a unique type of amacrine cell, called AII. This amacrine, in turn, contacts the axonal end-

Received April 15, 2004; revised July 15, 2004; accepted July 17, 2004.

This research was supported by National Institutes of Health Grants EY12654 (E.S.) and EY11115 (A.S.), The Telethon Foundation Project E0833, The Foundation Fighting Blindness (Owings Mills, MD), Research to Prevent Blindness (New York, NY), and Harold F. Falls Collegiate Professorship (to A.S.). We thank B. Howell, D. Hicks, R. Molday, and S. Nakanishi for the generous gift of antibodies.

Correspondence should be addressed to Enrica Strettoi, Neuroscienze, Neurofisiologia, Area della Ricerca, Consiglio Nazionale delle Ricerche, Via G. Moruzzi 1, Pisa 56100, Italy. E-mail: enrica.stretto@@in.cnr.it.

A. J. Mears's present address: University of Ottawa Eye Institute, Ottawa Health Research Institute, 501 Smyth Road, Ottawa, Ontario K1H 8L6, Canada.

DOI:10.1523/JNEUROSCI.2245-04.2004

Copyright $\odot 2004$ Society for Neuroscience $\quad$ 0270-6474/04/247576-07\$15.00/0 ings of the cone bipolar cells that, finally, are presynaptic to ganglion cells (Strettoi et al., 1992). Therefore, rod and cone pathways are separated at their first synapse in the outer retina but partially overlap proximally. Photoreceptors send their signals also to horizontal cells through synapses established in the outer part of the retina. Rodents have a single type of horizontal cell; its cell body and dendrites are postsynaptic to cones, and its large axonal arborization receives synaptic input from rods (Peichl and Gonzalez-Soriano, 1994). The molecular events underlying the establishment of this exquisitely complex architecture during retinal development are poorly understood.

To investigate whether rods and cones are essential for morphological differentiation, proper layering, and connectivity of their second-order neurons, we studied cells of the rod pathway in a retina in which rods fail to differentiate and are replaced by cones. We took advantage of the unique retinal phenotype of a mouse in which the neural retina leucine zipper $(\mathrm{Nrl})$ gene has been deleted (Mears et al., 2001). Nrl encodes a basic-motif leucine zipper transcription factor, which is preferentially expressed in rods and necessary for their differentiation (Swaroop et al., 1992; Rehemtulla et al., 1996; Bessant et al., 1999; Swain et al., 2001; Zhu et al., 2003). Without Nrl, postmitotic photoreceptor precursors do not develop into rods; instead, they produce an excess of cones, generating a cone-only retina. Recent studies have demonstrated that the supernumerary cones of the $\mathrm{Nrl}$ knock-out $(\mathrm{Nrl}-\mathrm{/}-)$ retinas are functional and primarily express S-opsin, which is sensitive to short wavelength light (Mears et al., 2001; Zhu et al., 2003).

We have shown that integrity of dendritic arbors in bipolar cells depends on the presence of photoreceptors, i.e., dendrites do not form appropriately, and eventually retract, when photoreceptors degenerate as a consequence of genetic mutations (Strettoi and Pignatelli, 2000). This happens in the retina of $r d / r d$ (retinal degeneration) mutant mice, in which rods carry a mutation 
of the rod-specific phosphodiesterase and undergo a massive degeneration from the second week of postnatal life; similarly, in cr $x-/-$ (cone rod homeobox) mice, in which photoreceptors degenerate in a timescale of several months, dendrites of bipolar cells retract progressively (Pignatelli et al., 2004).

This study addresses two crucial questions for our understanding of the development of the retinal circuitry. (1) When rods fail to develop, what is the destiny of neurons, such as rod bipolar cells, that as a rule receive their synaptic input from rods and not from cones? (2) How is the functional information from the enormous population of cones in the $\mathrm{Nrl} / \mathrm{/}-$ retina transmitted to ganglion cells?

We report that, in the retina of $\mathrm{Nrl}-/-$ mice, neurons of the rod pathway (specifically the rod bipolar cells, axonal arborizations of horizontal cells, and AII amacrine cells) are preserved; they display normal morphologies but now receive their input from the newly generated cones.

\section{Materials and Methods}

Twenty retinas from 18 -week-old $\mathrm{Nrl}-/-$ mice from the strain described by Mears et al. (2001) and six retinas from age-matched wild-type (wt) animals were used. Experiments were done in compliance with the Association for Research in Vision and Ophthalmology statement and with the Italian laws for the use of animals in research. Animals were anesthetized by intraperitoneal injection of avertin and perfused transcardially with $4 \%$ paraformaldehyde in $0.1 \mathrm{~m}$ phosphate buffer, $\mathrm{pH} 7.4$, and their eyes were enucleated. Frozen retinal sections were treated for immunocytochemistry as described by Strettoi et al. (2002) and examined with a Leica (Nussloch, Germany) TCS-NT confocal microscope equipped with an argon-krypton laser. Primary antibodies used were as follows: protein kinase C (PKC), calbindin, neurofilament $200 \mathrm{kDa}$, kinesin II, and rhodopsin (Sigma, St. Louis, MO); bassoon (Chemicon, Temecula, CA); rod, light-sensitive channel (from R. Molday, University of British Columbia, Vancouver, British Columbia, Canada); arrestin (from D. Hicks, Centre Hospitalier Universitaire, Strasbourg, France); Dab-1 (the product of the disabled-1 gene; from B. Howell, National Institutes of Health, Bethesda, MD); and metabotropic glutamate receptor 6 (mGluR6) (from S. Nakanishi, Keio University School of Medicine, Tokyo, Japan). Cones were labeled with HRP-peanut agglutinin (PNA) (Sigma).

For electron microscopy, staining with PKC antibodies was performed on free-floating $50 \mu \mathrm{m}$ sections of six retinas; the antigen-antibody complex was visualized by a biotin-labeled secondary antibody, followed by avidin-biotin-peroxidase complex and DAB-nickel (Vector Laboratories, Burlingame, CA). The sections were then fixed with aldehydes, postfixed with osmium tetroxide, dehydrated in ethanol, and embedded in Epon-Araldite plastic for electron microscopy. Ultrathin vertical sections were examined with a Jeol (Peabody, MA) 1200 EXII electron microscope. Routine electron microscopy was also performed on four additional wt and mutant retinas perfusion fixed and embedded in plastic, according to the method described by Jeon et al. (1998).

\section{Results}

The retina of $\mathrm{Nrl}-\mathrm{/}-$ mice displays a normal general morphology and lamination (Fig. 1). Two distinctive features are obvious after initial analysis: the photoreceptor outer segments are shorter (Figs. 1, 2), and the outer plexiform layer (opl) is undulating (Fig. 2).

The $\mathrm{Nrl}-/-$ retina exhibits a pure population of cones, of which the apparent density is approximately the same as the total photoreceptor density in control retinas. Staining with PNA, which binds selectively to cones, shows only the small population of cones typical of rodent retinas in wt mice, whereas in the $\mathrm{Nrl}-/-$ retina, the entire photoreceptor layer is heavily labeled (Fig. 2). Cone synaptic terminals in the opl are also labeled and form a continuous layer (Fig. 2). In addition, conventional stain-
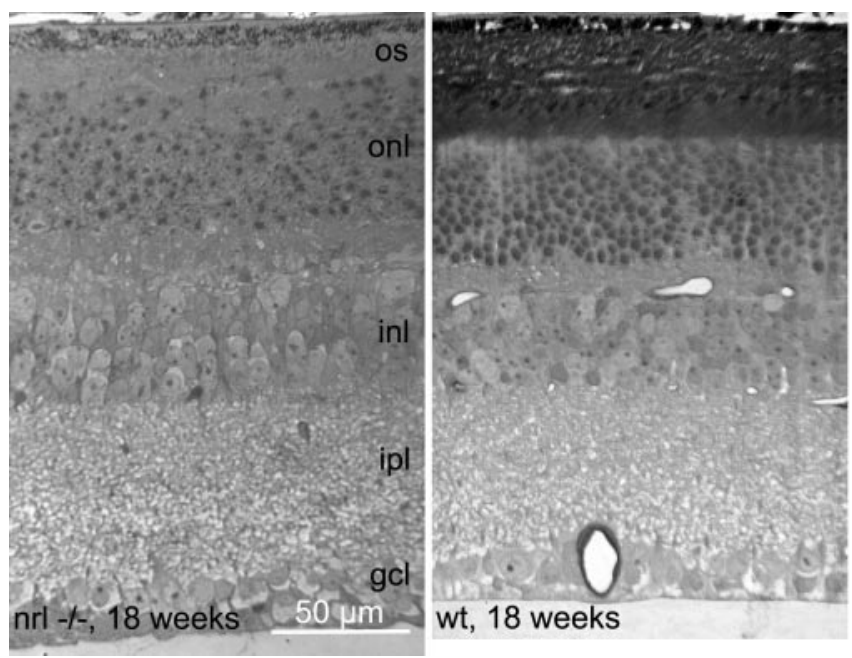

wt, 18 weeks

Figure 1. Vertical sections of $\mathrm{Nrl}-\mathrm{/}-$ and retinas from control (wt) mice, conventionally stained with toluidine blue. Photoreceptor outer segments (os) are short in the knock-out. onl, Outer nuclear layer; inl, inner nuclear layer; ipl, inner plexiform layer; gcl, ganglion cell layer.
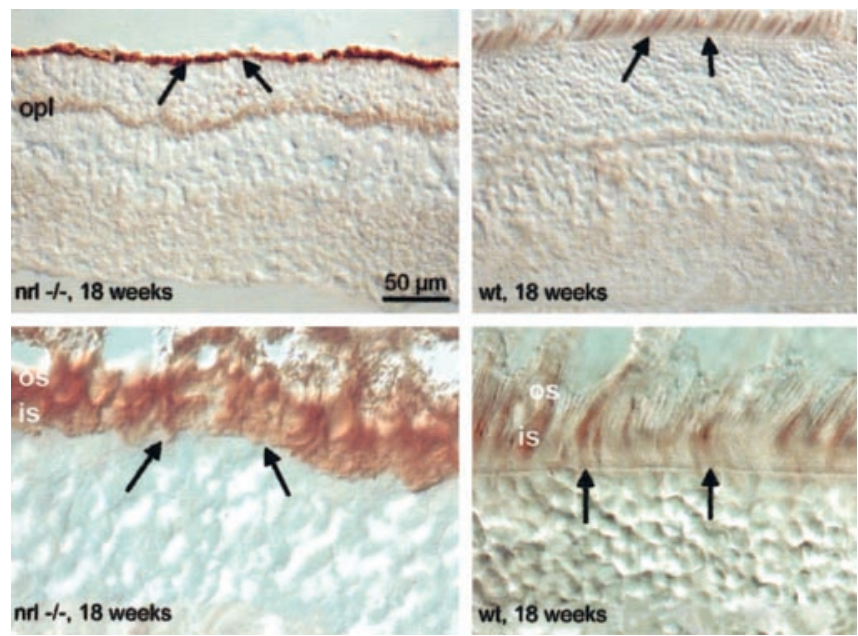

Figure 2. Peanut lectin conjugated to peroxidase (dark staining) labels a continuous layer of cone outer and inner segments in the $\mathrm{Nrl}-/$ - retina; only 3\% of photoreceptors (the cones) are stained in the retina of the wt (arrows). Note the irregular course of the outer plexiform layer in the $\mathrm{Nrl}-\mathrm{/}-$ retina.

ing with basic nuclear dyes, as shown in Figure. 1, shows that photoreceptor nuclei in the $\mathrm{Nrl}-/-$ are less dense than the in wt counterpart; this is caused by the fact that rod chromatin is more condensed than cone chromatin.

Electron microscopy shows that the opl of the $\mathrm{Nrl}-/-$ retina is less regular than that of the wt: synaptic terminals have a smaller size than cone pedicles but are larger than typical rod spherules (Fig. 3). They occupy at least two rows in the opl, unlike wt cone pedicles, which form a single layer. They are penetrated by multiple processes of second-order neurons, as in wt cone pedicles. These processes establish typical invaginating (ribbon) contacts, as shown in Figure 3, in which several terminal dendrites, labeled by an asterisk, can be observed in close apposition to synaptic ribbons in the cone pedicles. Basal contacts, characterized by a layering of electron-dense material at the site of the junction, are also clearly visible (Fig. 3): they are presumably established between cone pedicles and dendrites of selected types of cone bipolar cells.

None of the photoreceptors of the $\mathrm{Nrl}-/-$ retina stain with 

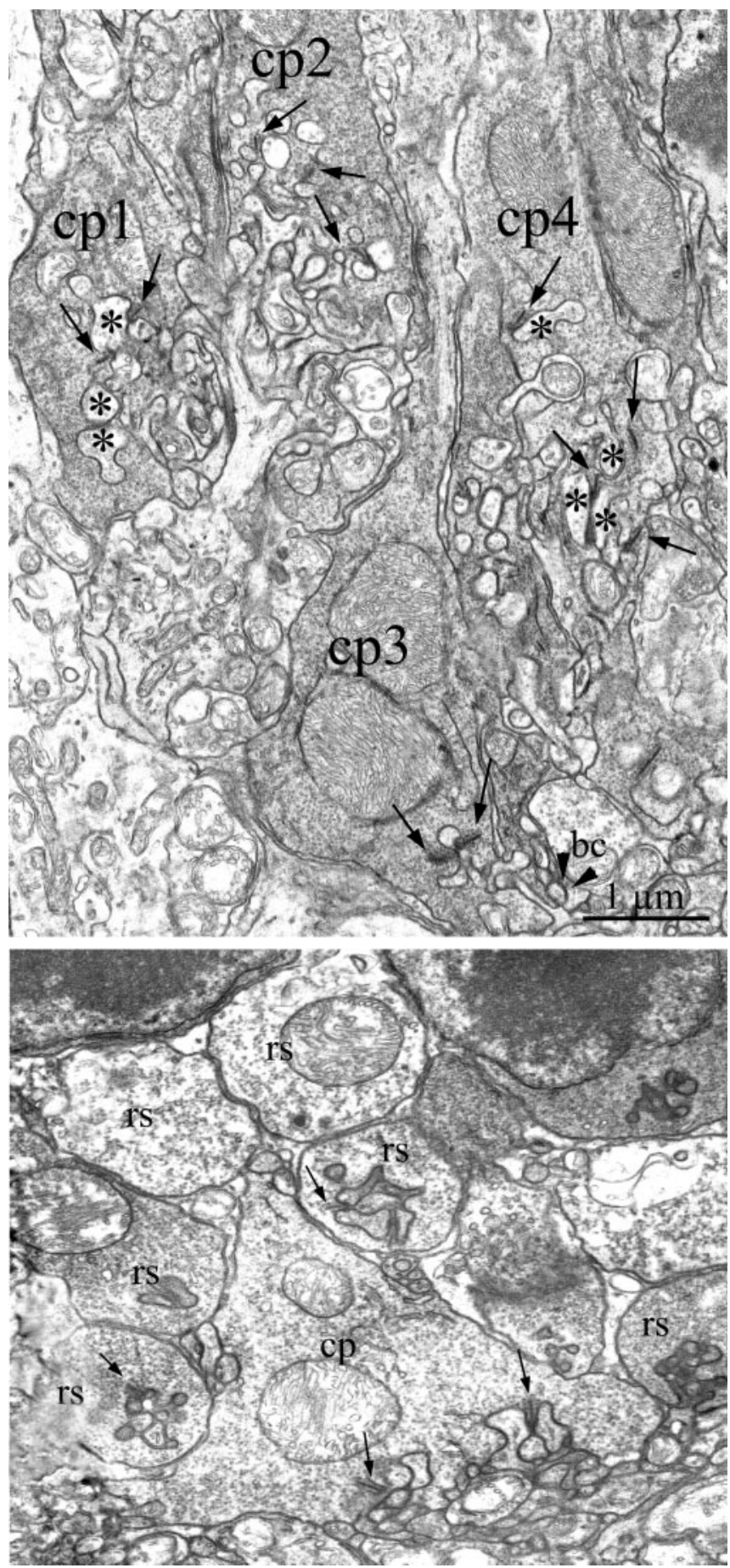

Figure 3. Electron micrographs of the opl in $\mathrm{Nrl}-\mathrm{l}-$ (top) and wt (control) retinas (bottom). Note the irregular size of cone pedicles (cp) in the mutant and the presence of multiple processes of second-order neurons that penetrate them (labeled by asterisks). Each cone pedicle displays more than one synaptic ribbon (arrows). Basal contacts (bc) are also clearly distinguishable (arrowheads). One cone pedicle, of typical triangular shape, is visible in the wt, surrounded by several rod spherules (rs).

antibodies against rod-specific proteins, such as rhodopsin and the light-sensitive channel (Fig. 4). This is in agreement with the recently reported lack of expression of the corresponding genes in the knock-out retina (Yoshida et al., 2004).

The rod pathway in the $\mathrm{Nrl}-/-$ mouse

Rod bipolar cells are well characterized neurons of the mammalian retina. In addition to being postsynaptic to rods, these cells
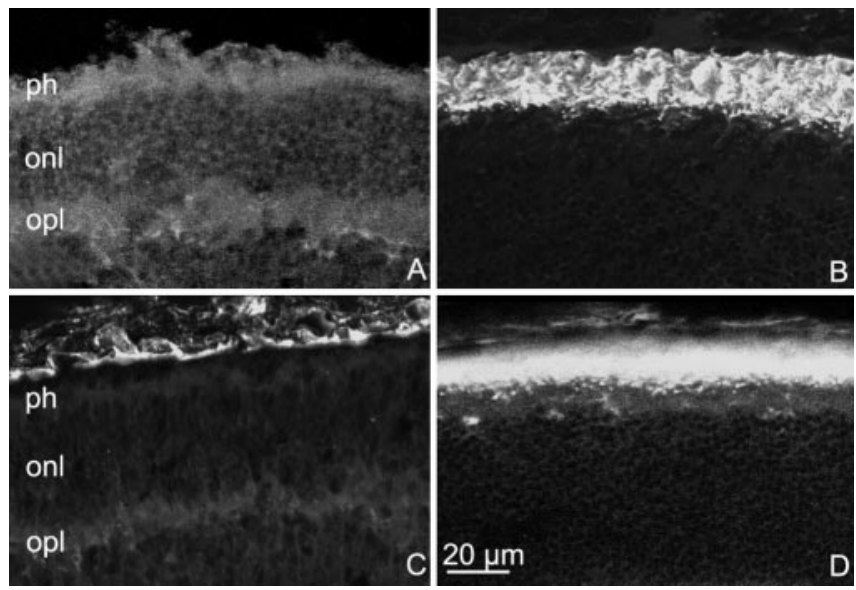

Figure 4. Photoreceptors of the $\mathrm{Nrl}-/$ - retina lack normal rod markers. Rhodopsin is absent from the photoreceptor layer (ph) of the $\mathrm{Nrl}-/$ - retina $(A)$; rhodopsin antibodies intensely stain rods in the wild type $(B)$. Also, antibodies against the light-sensitive rod channel fail to label rods in the $\mathrm{Nr}-\mathrm{I}-$ retina ( $($ ); they label bright rod outer segments in the wild type (D). onl, Outer nuclear layer.

are uniquely identified by a set of specific morphological features, which include (1) a bushy arborization in the opl with numerous dendrites irradiating from the cell body, (2) the localization of the axonal arborization in the innermost stratum of the inner plexiform layer (ipl) (the s5), (3) the distinctive anatomy of the axonal arborization, consisting of a tight cluster of large endings, (4) the localization of glutamate metabotropic synaptic receptors (mGluR6) on their dendritic tips (Takao et al., 2000), a feature they share with subsets of cone bipolar cells, (5) the accumulation of the $\alpha$ isoform of PKC, so that they can be stained with antiPKC $\alpha$ antibodies (Usuda et al., 1991), and (6) a specific set of synaptic connections, with a major output onto the vitreal dendrites of AII amacrine cells (Strettoi et al., 1992).

In the retina of $\mathrm{Nrl}-/-$ mouse, cells having the features of rod bipolar cells are present, and they appear undistinguishable from those of the retina in the wild-type mouse.

Figure 5 illustrates typical rod bipolar cells stained in green with anti-PKC $\alpha$ antibodies in the retina of $\mathrm{Nrl}-/-$ mice. These cells carry clusters of metabotropic glutamate receptors (mGluR6) on their dendrites, which appear as a characteristic cloud of fluorescent puncta (Fig. 5, inset).

Figure $6 \mathrm{~A}$ illustrates retinal sections double-labeled with $\mathrm{PKC}$ (green) and arrestin (red) antibodies. The latter bind to a phototransduction G-protein that highlights the full profiles of cone photoreceptors, including their synaptic terminals (Hendrickson and Hicks, 2002). The intimate association of rod bipolar dendrites with the cone synaptic terminals is obvious. Figure $6, B$ and $C$, shows a retinal section stained with $\mathrm{PKC}$ and kinesin antibodies. Kinesins are motor proteins associated with the synaptic ribbons (Muresan et al., 1999) that are contained within the synaptic terminals of photoreceptors. Therefore, in the $\mathrm{Nrl}-/-$ retina, kinesin antibodies label the presynaptic active zone of the synapses between cone and bipolar cells and between cone and horizontal cells. The fluorescent ribbons are intimately associated with the dendrites of bipolar cells. Similar results were obtained by using PKC staining in combination with antibodies against bassoon, another protein localized at the presynaptic active zone of ribbon synapses in the outer retina (data not shown) (Haverkamp et al., 2001; Dick et al., 2003).

Finally, electron microscopy of the $\mathrm{Nrl}-\mathrm{/}-$ retina confirms that PKC-positive dendrites of rod bipolar cells terminate within 


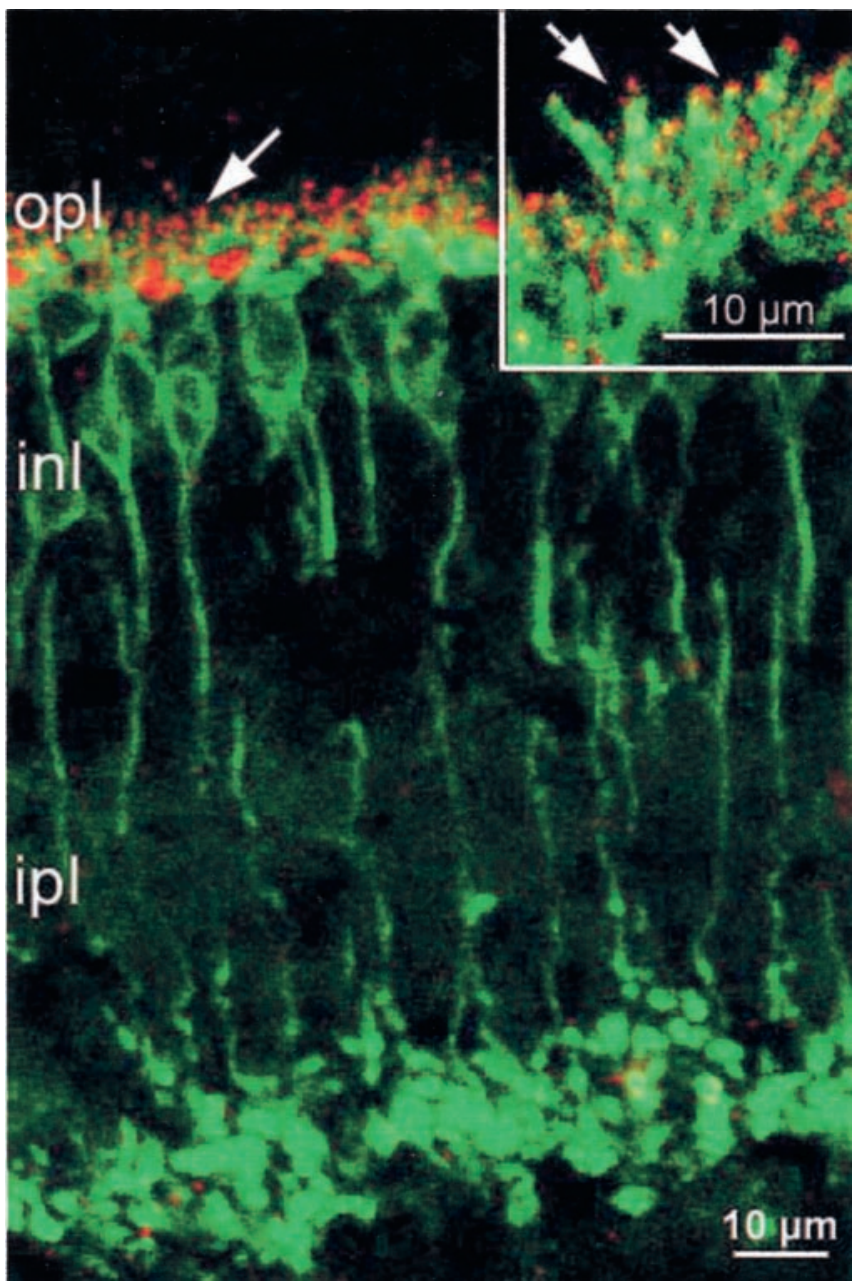

Figure 5. PKC staining of rod bipolar cells (green) in the $\mathrm{Nr}-1-$ retina shows their normal morphology. They carry clusters of mGluR6 receptors (red, arrows) on the outer margin of their dendrites, in the opl tips (inset). Additional mGluR6 puncta decorate the dendritic tips of depolarizing cone bipolar cells (unlabeled).
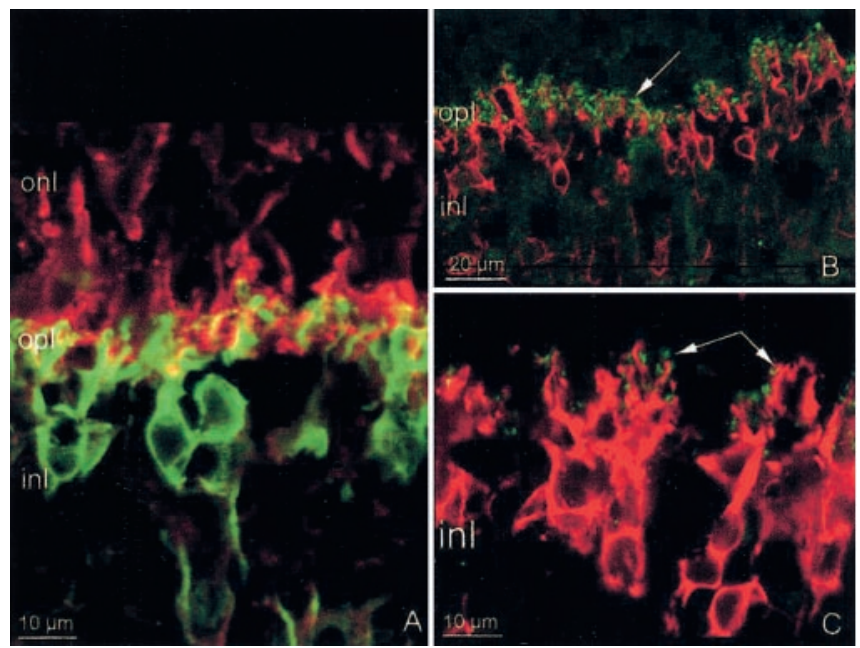

Figure 6. A, Rod bipolar cells, stained by PKC (green), have dendrites intermingling in the opl with synaptic endings of cones, labeled red by arrestin. B, C, Synaptic ribbons are labeled inside cone synaptic terminals by kinesin antibodies (green staining). Ribbons are in close proximity to postsynaptic dendrites of rod bipolar cells, labeled red by PKC antibodies. the synaptic invaginations of the cone pedicles, in close association with the synaptic ribbons (Fig. 7).

AII amacrine cells, the neurons of the mammalian retina that represent a link between the rod and the cone pathways, are conserved in the $\mathrm{Nrl}-/-$ mouse. Their typical bistratified arborization was revealed by means of antibodies to Dab-1, the gene product of the disabled-1 gene (Rice and Curran, 2000) (Fig. 7); their tufted vitreal dendrites costratify with the axonal arborizations of rod bipolar cells in the deepest stratum (s5) of the inner plexiform layer (Fig. 8).

Like rod bipolar cells, the axonal arbors of the horizontal cells in the $\mathrm{Nrl}-/-$ retina appear to succeed in establishing novel connections with the cones. The axonal compartments of individual horizontal cells can be identified after neurofilament immunostaining and also by means of calbindin antibodies (Fig. 9, red signal). Small digitations emerging from the main branches of the axonal arborization are decorated with synaptic ribbons (labeled in green by kinesin antibodies in Fig. 9), which identify the site of synaptic contact with the cone pedicles. Thus, axonal arbors of horizontal cells of the $\mathrm{Nrl}-/$ - retina retain their original staining properties and distinctive morphology. This is clearly visible in whole-mount retinal preparations stained with neurofilament antibodies (data not shown).

In summary, the rod bipolar cells, the axonal arbors of horizontal cells, and AII amacrines (the key neurons of the rod pathway) are all present in the retina of $\mathrm{Nrl}-/-$ mice. Their overall morphology, the pattern of stratification of their processes, and their staining properties are the same as those exhibited by their counterparts in the retina of the wild-type mice. Hence, it appears that all of these features are not instructed by the establishment of synaptic contacts between second-order neurons and the specific matching class of photoreceptor(s) in the outer retina.

\section{Discussion}

Using the unique paradigm of a mouse mutant in which rods are absent and all photoreceptors appear to be cones, we demonstrate that cone photoreceptors become connected with the neurons of the rod pathway.

In the $\mathrm{Nrl}-/$ - retina, rod bipolar cells, although postsynaptic to cones at ribbon synapses, display features typical of their counterparts in the retina of the wild-type mouse: a normal morphology, similar staining properties, the appropriate pattern of axonal stratification in the ipl, and a normal complement of mGluR6 receptors on their dendrites. In the inner retina, their axonal arbors costratify with (and are most likely presynaptic to) AII amacrine cells, which also display a normal morphology. Electrophysiological evidence shows that these cone-driven rod bipolars respond to light, because the photopic b-wave of the electroretinogram (a depolarizing response generated by inner retinal cells) is much larger than in the wild-type retina (Mears et al., 2001). Similar conclusions can be drawn by analyzing the morphology and pattern of connections of the axonal arborization of horizontal cells, which are normally postsynaptic to rods. In the $\mathrm{Nrl}-/-$ retina, the horizontal cells appear normal. Their axonal arbors have multiple processes that establish close topographical relations with the synaptic ribbons of cone photoreceptors, suggesting that they receive chemical synaptic contacts from them. Basically, all of the anatomical details that comprise the core definition of rod bipolar and horizontal cells are indeed preserved in the retina of $\mathrm{Nrl}-/-$ mice.

These findings have several fundamental implications. (1) They suggest that the presence of viable photoreceptors is crucial for the development and maintenance of normal second-order 
neurons. (2) They reveal an underlying synaptic plasticity in the retina, because a neuronal circuit normally driven by rods can subserve a different function when driven by cones.

It has been proposed that maintenance of a normal dendritic tree requires the presence of viable photoreceptors. In the $r d / r d$ mouse retina, in which rods degenerate in a time window partially overlapping with synaptogenesis, rod bipolar and horizontal cells never develop their dendrites properly (Strettoi and Pignatelli, 2000; Strettoi et al., 2002). Later, cone bipolar cells also retract their dendrites (Strettoi et al., 2002). Dendritic retraction also occurs in other strains of mice with photoreceptor degeneration (Pignatelli et al., 2004). In the case of rod bipolar cells, incomplete dendritic development in the $r d / r d$ retina is associated with the lack of electrophysiological responses to the exogenous application of glutamate, the photoreceptor neurotransmitter (Varela et al.,2003). Similarly, the development and maintenance of dendritic arbors in neurons of the central auditory nuclei require the integrity of their primary cochlear afferents (Rubel and Fritzsch, 2002). Our data support the hypothesis that photoreceptors (and presumably synaptic activity) are necessary for the maintenance of dendrites in second-order neurons; however, photoreceptors do not need to belong to a specific type to provide support to other retinal cells. Even photoreceptors of a different type (i.e., cones instead of rods) can support proper development of second-order neuron morphology.

It is conceivable that several of the unique features used to define a neuron as belonging to a specific anatomical type are shaped by their interactions (trophic, metabolic, and synaptic) with afferent cells. The pattern and level of stratification of the axonal arbors of bipolar cells in the inner plexiform layer, which reflect their functional diversity, are not influenced by major changes in retinal architecture: the neonatal elimination of ganglion cells, which are their major target (Gunhan-Agar et al., 2000), the selective removal of cholinergic amacrine cells (Gunhan et al., 2002), the formation of supernumerary neurons in the inner nuclear layer (Strettoi and Volpini, 2002), or an imbalance in afferent activity (Bodnarenko et al., 1995), do affect the number of bipolar cells but not the connectivity in the ipl. Our data demonstrate that the lamination of rod bipolar cells, and probably the wiring of their axons, are not affected by the absence of their normal presynaptic partners. The reeler mouse is a rare mutant that shows a specific deficit of the product of the gene disabled-1, expressed in AII amacrine cells (Rice and Curran, 2000); reeler mice do have an abnormal lamination of bipolar cells in the ipl. Thus, an important aspect of retinal development is that the stratification of the axon of bipolar cells is either determined by an intrinsic program or influenced by molecules expressed in subsets of amacrine cells.

Similarly, the mosaic of horizontal cells is particularly resistant to changes in the overall retinal architecture, including the degeneration of photoreceptors and the absence of rod input (Raven and Reese, 2003). We show that, in the $\mathrm{Nrl}-/-$ retina, horizontal cells exhibit remarkable morphological integrity. Basically, their axonal arbors have been recruited, establishing synaptic contacts with newly formed cone photoreceptors.

In the rodent retina, cone bipolar cells exist that form a small number of synaptic contacts with rods (Tsukamoto et al., 2001). Horizontal cells do form connections with cones as a normal pattern of their circuitry. However, connections between cones and rod bipolar cells have only exceptionally been reported in a normal mammal (Dacheux and Raviola, 1986). These connections can form ectopically in the retina of $r d / r d$ mutant mice, as well as in the retina of transgenic swine with rod degeneration (Peng et al., 2000). In virtue of the fact that photoreceptors degenerate completely in the retina of such mutants, these ectopic connections can be considered as examples of retinal plasticity with transient effects. However, our studies on the $\mathrm{Nrl} / \mathrm{/}-$ retina indicate that there are no major obstacles for establishment of a connectivity involving neurons normally not linked to each other.

Our studies also raise several important questions. If bipolar cells are not too selective in terms of choice of their presynaptic partners, what are the cues that make them discriminate between rods and cones during normal development? Similarly, what makes a horizontal cell axonal arbor select rods among nearby cones in normal circumstances? The timing of cell birth during retinal differentiation is expected to be important in determining 


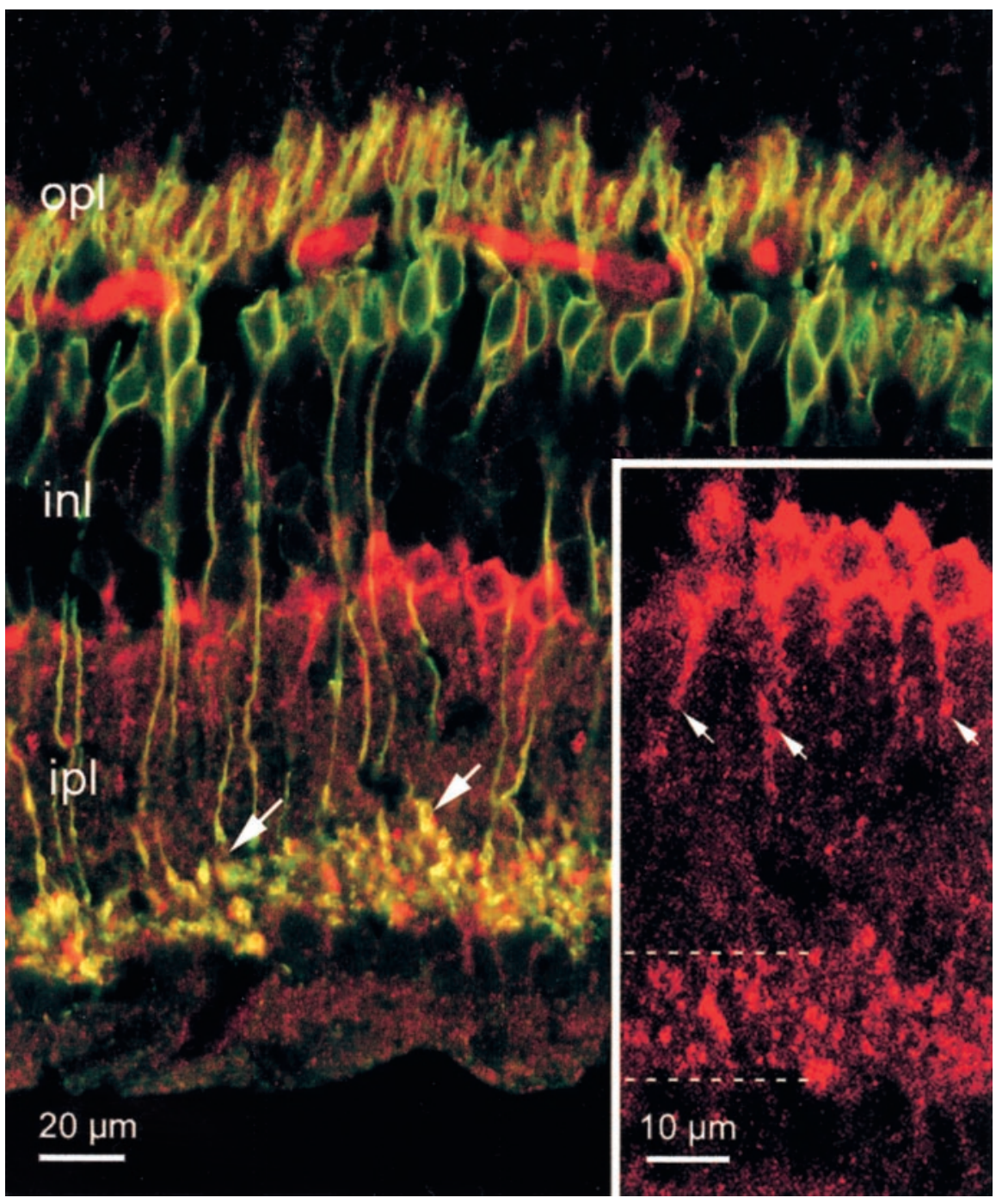

Figure 8. The axonal arbors of rod bipolar cells (PKC staining, green) costratify with the innermost dendrites of all amacrine cells (arrows), stained by disabled- 1 antibodies (red). All cells have a typical morphology (inset), with main dendrites in the outer part of the ipl (arrows) and terminal processes in the inner lamina of the ipl, indicated by dashed lines.
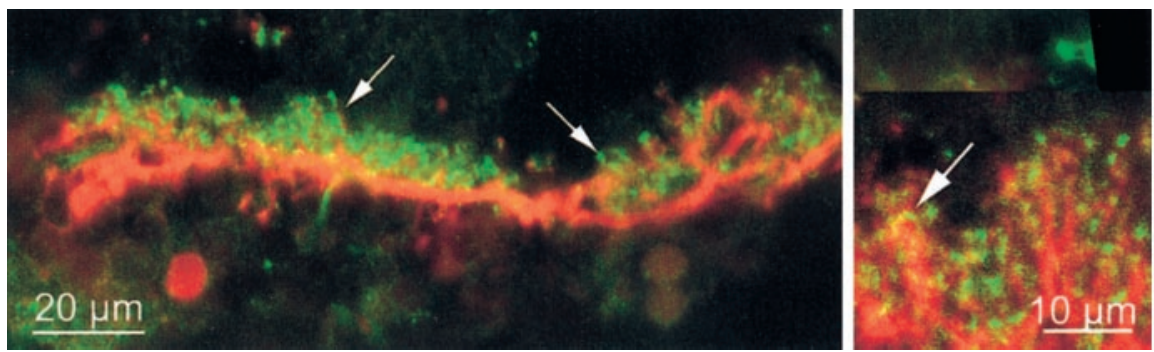

Figure 9. Horizontal cell axonal arbors. Calbindin labeling (red) shows a typical axonal arbor of one horizontal cell in the $\mathrm{Nrl}-/-$ retina, decorated by clusters of synaptic ribbons stained by kinesin (green) inside cone terminals. The inset on the right shows a high-power confocal micrograph illustrating the colocalization of kinesin and horizontal cell dendrites (arrow) in the opl.

the precision and specificity of synaptic connections. However, rods have a prolonged window of cell birth, overlapping with those of cones and bipolar cells (Carter-Dawson and LaVail, 1979; La Vail et al., 1991); it is difficult to imagine a temporal match so accurate in the genesis of synaptic partners as to ensure their highly precise connectivity.

The behavior of inner retinal cells in genetically altered animals is of interest for understanding cell-to-cell interactions in retinal development, because only a few of the guidance cues that drive proper retinal connectivity have been identified (Wong and Ghosh, 2002). Plastic changes in the retinal wiring diagram are also of potential relevance in therapeutic approaches aimed at restoring vision in retinas with photoreceptor degeneration, such as retinitis pigmentosa (Lund et al., 2001). Based on the studies reported here, we hypothesize that, if photoreceptors (or photoreceptor neuroblasts) are used for transplantation, under certain conditions they may be able to recruit second-order neurons of whatever type to establish functioning synapses.

\section{References}

Bessant DA, Payne AM, Mitton KP, Wang QL, Swain PK, Plant C, Bird AC, Zack DJ, Swaroop A, Bhattacharya SS (1999) A mutation in NRL is associated with autosomal dominant retinitis pigmentosa. Nat Genet 21:355-356.

Bodnarenko SR, Jeyarasasingam G, Chalupa LM (1995) Development and regulation of dendritic stratification in retinal ganglion cells by glutamate-mediated afferent activity. J Neurosci 15:7037-7045.

Buffelli M, Burgess RW, Feng G, Lobe CG, Lichtman JW, Sanes JR (2003) Genetic evidence that relative synaptic efficacy biases the outcome of synaptic competition. Nature 424:430-434.

Carter-Dawson LD, LaVail MM (1979) Rods and cones in the mouse retina. II. Autoradiographic analysis of cell generation using tritiated thymidine. J Comp Neurol 188:263-272.

Curcio CA, Sloan KR, Kalina RE, Hendrickson AE (1990) Human photoreceptor topography J Comp Neurol 292:497-523.

Dacheux RF, Raviola E (1986) The rod pathway in the rabbit retina: a depolarizing bipolar and amacrine cell. J Neurosci 6:331-345.

Dick O, tom Dieck S, Altrock WD, Ammermuller J, Weiler R, Garner CC, Gundelfinger ED, Brandstatter JH (2003) The presynaptic active zone protein bassoon is essential for photoreceptor ribbon synapse formation in the retina. Neuron 37:775-786.

Gunhan E, Choudary PV, Landerholm TE, Chalupa LM (2002) Depletion of cholinergic amacrine cells by a novel immunotoxin does not perturb the formation of segregated on and off cone bipolar cell projections. J Neurosci 22:2265-2273.

Gunhan-Agar E, Kahn D, Chalupa LM (2000) Segregation of on and off bipolar cell axonal arbors in the absence of retinal ganglion cells. J Neurosci 20:306-314.

Haverkamp S, Grunert U, Wassle H (2001) Localization of kainate receptors at the cone pedicles of the primate retina. J Comp Neurol 436:471-486.

Hendrickson A, Hicks D (2002) Distribution and density of medium- and short-wavelength selective cones in the domestic pig retina. Exp Eye Res 74:435-444.

Jeon CJ, Strettoi E, Masland RH (1998) The major cell populations of the mouse retina. J Neurosci 18:8936-8946.

Kasthuri N, Lichtman JW (2003) The role of neuronal identity in synaptic competition. Nature 424:426-430. 
Katz LC, Shatz CJ (1996) Synaptic activity and the construction of cortical circuits. Science 274:1133-1138.

La Vail MM, Rapaport DH, Rakic P (1991) Cytogenesis in the monkey retina. J Comp Neurol 309:86-114.

Lund RD, Kwan AS, Keegan DJ, Sauve Y, Coffey PJ, Lawrence JM (2001) Cell transplantation as a treatment for retinal disease. Prog Retin Eye Res 20:415-449.

Mears AJ, Kondo M, Swain PK, Takada Y, Bush RA, Saunders TL, Sieving PA, Swaroop A (2001) Nrl is required for rod photoreceptor development. Nat Genet 29:447-452.

Muresan V, Lyass A, Schnapp BJ (1999) The kinesin motor KIF3A is a component of the presynaptic ribbon in vertebrate photoreceptors. J Neurosci 19:1027-1037.

Peichl L, Gonzalez-Soriano J (1994) Morphological types of horizontal cell in rodent retinae: a comparison of rat, mouse, gerbil, and guinea pig. Vis Neurosci 11:501-517.

Peng YW, Hao Y, Petters RM, Wong F (2000) Ectopic synaptogenesis in the mammalian retina caused by rod photoreceptor-specific mutations. Nat Neurosci 3:1121-1127.

Pignatelli V, Cepko CL, Strettoi E (2004) Inner retinal abnormalities in a mouse model of Leber's congenital amaurosis. J Comp Neurol 469:351-359.

Raven MA, Reese BE (2003) Mosaic regularity of horizontal cells in the mouse retina is independent of cone photoreceptor innervation. Invest Ophthalmol Vis Sci 44:965-973.

Rehemtulla A, Warwar R, Kumar R, Ji X, Zack DJ, Swaroop A (1996) The basic motif-leucine zipper transcription factor Nrl can positively regulate rhodopsin gene expression. Proc Natl Acad Sci USA 93:191-195.

Rice DS, Curran T (2000) Disabled-1 is expressed in type AII amacrine cells in the mouse retina. J Comp Neurol 424:327-338.

Rubel EW, Fritzsch B (2002) Auditory system development: primary auditory neurons and their targets. Annu Rev Neurosci 25:51-101.

Sengpiel F, Kind PC (2002) The role of activity in development of the visual system. Curr Biol 12:R818-R826.

Strettoi E, Pignatelli V (2000) Modifications of retinal neurons in a mouse model of retinitis pigmentosa. Proc Natl Acad Sci USA 97:11020-11025.
Strettoi E, Volpini M (2002) Retinal organization in the bcl-2overexpressing transgenic mouse. J Comp Neurol 446:1-10.

Strettoi E, Raviola E, Dacheux RF (1992) Synaptic connections of the narrow-field, bistratified rod amacrine cell (AII) in the rabbit retina. J Comp Neurol 325:152-168.

Strettoi E, Porciatti V, Falsini B, Pignatelli V, Rossi C (2002) Morphological and functional abnormalities in the inner retina of the $\mathrm{rd} / \mathrm{rd}$ mouse. J Neurosci 22:5492-5504.

Swain PK, Hicks D, Mears AJ, Apel IJ, Smith JE, John SK, Hendrickson A, Milam AH, Swaroop A (2001) Multiple phosphorylated isoforms of NRL are expressed in rod photoreceptors. J Biol Chem 276:36824-36830.

Swaroop A, Xu JZ, Pawar H, Jackson A, Skolnick C, Agarwal N (1992) A conserved retina-specific gene encodes a basic motif/leucine zipper domain. Proc Natl Acad Sci USA 89:266-270.

Takao M, Morigiwa K, Sasaki H, Miyoshi T, Shima T, Nakanishi S, Nagai K, Fukuda Y (2000) Impaired behavioral suppression by light in metabotropic glutamate receptor subtype 6-deficient mice. Neuroscience 97:779-787.

Tsukamoto Y, Morigiwa K, Ueda M, Sterling P (2001) Microcircuits for night vision in mouse retina. J Neurosci 21:8616-8623.

Usuda N, Kong Y, Hagiwara M, Uchida C, Terasawa M, Nagata T, Hidaka H (1991) Differential localization of protein kinase C isozymes in retinal neurons. J Cell Biol 112:1241-1247.

Varela C, Igartua I, De la Rosa EJ, De la Villa P (2003) Functional modifications in rod bipolar cells in a mouse model of retinitis pigmentosa. Vision Res 43:879-885.

Wong RO, Ghosh A (2002) Activity-dependent regulation of dendritic growth and patterning. Nat Rev Neurosci 3:803-812.

Yoshida S, Mears AJ, Friedman JS, Carter T, He S, Oh E, Jing Y, Farjo R, Fleury G, Barlow C, Hero AO, Swaroop A (2004) Expression profiling of the developing and mature $\mathrm{Nrl}-/-$ mouse retina: identification of retinal disease candidates and transcriptional regulatory targets of $\mathrm{Nrl}$. Hum $\mathrm{Mol}$ Genet 13:1487-1503.

Zhu X, Brown B, Li A, Mears AJ, Swaroop A, Craft CM (2003) GRK1dependent phosphorylation of $S$ and $M$ opsins and their binding to cone arrestin during cone phototransduction in the mouse retina. J Neurosci 23:6152-6160. 